\title{
Fuzzy Decsion Based Soft Multi Agent Controller for Speed Control of Three Phase Induction Motor
}

\author{
Rathod Nirali ${ }^{1}$, S.K.Shah ${ }^{2}$ \\ ${ }^{1}$ Electrical Engg.Dept., S.V.I.T, Vasad,India \\ nirali_ee@yahoo.co.in \\ ${ }^{2}$ Electrical Engg.Dept., Faculty of Technology \& Engineering, M.S.U. Baroda,India \\ satishkshah_2005@yahoo.com
}

\begin{abstract}
:
Soft Multi agent controllers are used for control of complex systems. Induction motor is widely used in industrial applications. But due to its highly non linear behavior its control is very complex. Non linear speed control techniques are employed to improve dynamic performance of electric drives.

Paper describes multi agent based approach to control speed of Induction motor. Design and simulation of Multi Agent System is developed for Indirect vector controlled 3-phase Induction motor. Soft computing techniques are used for implementation. Three types of controllers: Classical controller (PI), Fuzzy (FLC) \& Neural Network ANN) are constitutant of the Multi Agent system. Simulated speed responses parameters viz: rise time, steady state error and overshoot of SIMULINK models are used to make by a fuzzy logic is used to select the best controller from the constituents.
\end{abstract}

Key words:

Induction motor, Vector control, Artificial Neural Network (ANN), PI controller, Fuzzy Logic (FLC), Multi Agent System (MAS)

\section{Introduction}

An agent represents an abstract entity that is able to solve a defined problem. Agents are combined into a multi-agent system, such that the overall multi-agent system can solve a more complex problem. Induction motors are widely used in industries due to its robust construction, low maintenance and ease of availability in wide power range. But Induction Motors also suffer from disadvantage of controllability due to complex mathematical model and its nonlinear behavior.

In this paper the Multi Agent System is developed for indirect vector control of Three Phase Induction Motor in which motor is operated like separately excited D.C.Motor. This method enables the control of field and torque of Induction Motor independently.

\section{Multi Agent System}

Agent is a system, which has the ability to accomplish the tasks that the user has defined. A multi-agent system is a system comprising two or more agents or intelligent agents. Multi-Agent Systems (MAS) are systems where there is no central control: the agents receive their inputs from the other system or other agents and use these inputs to apply the appropriate actions. 
Such systems are assembled from autonomously interacting agents. Agents are small software programs, which have some type of intelligence. Their individual behavior is able to control complex system. Coordination between agents is the one of the important element in the construction of MAS. [3]

The basic characteristics of MAS are lack of global control, decentralized data and asynchronous computation. Distributed problem, Robustness, Scalability, Simpler implementation, Parallism are some of the advantages of MAS. [3]

\section{Indirect Vector Control}

The Figure.1 shows Vector controlled Induction motor drive system. The Induction motor is fed by current controlled voltage source inverter. The motor current is decomposed into two components direct axis current $\mathrm{i}_{\mathrm{ds}}$ and quadrature axis current $\mathrm{i}_{\mathrm{qs}}$ with respect to synchronously rotating reference frame. These currents produce flux and torque respectively. To improve performance of Drive Indirect Vector control method is preferred. This method uses indirect procedure to ensure presence of rotor flux in the direct axis.

Indirect vector control is complex, but it is inherently four quadrant speed control. It can easily cover zero speed.

The inverter generates currents $i_{a}, i_{b}, i_{c}$ as dictated by the corresponding command currents $i_{a}{ }^{*}$, $\mathrm{i}_{\mathrm{b}}{ }^{*}, \mathrm{i}_{\mathrm{c}}{ }^{*}$ from the controller. The machine terminal phase currents $\mathrm{i}_{\mathrm{a}}, \mathrm{i}_{\mathrm{b}}, \mathrm{i}_{\mathrm{c}}$ are converted to $\mathrm{i}_{\mathrm{ds}}{ }^{*}$ and $\mathrm{i}_{\mathrm{qs}}{ }^{*}$ components by Park's transformation.

These current components are then converted to synchronously rotating reference frame by the unit vector components $\cos \theta_{\mathrm{e}}$ and $\sin \theta_{\mathrm{e}}$ before applying them to the $\mathrm{d}^{\mathrm{e}}-\mathrm{q}^{\mathrm{e}}$ machine model. The controller makes two stages of inverse transformation, so that control currents $\mathrm{i}_{\mathrm{ds}}{ }^{*}$ and $\mathrm{i}_{\mathrm{qs}}{ }^{*}$ correspond to the machine currents $i_{\mathrm{ds}}$ and $\mathrm{i}_{\mathrm{qs}}$ respectively.

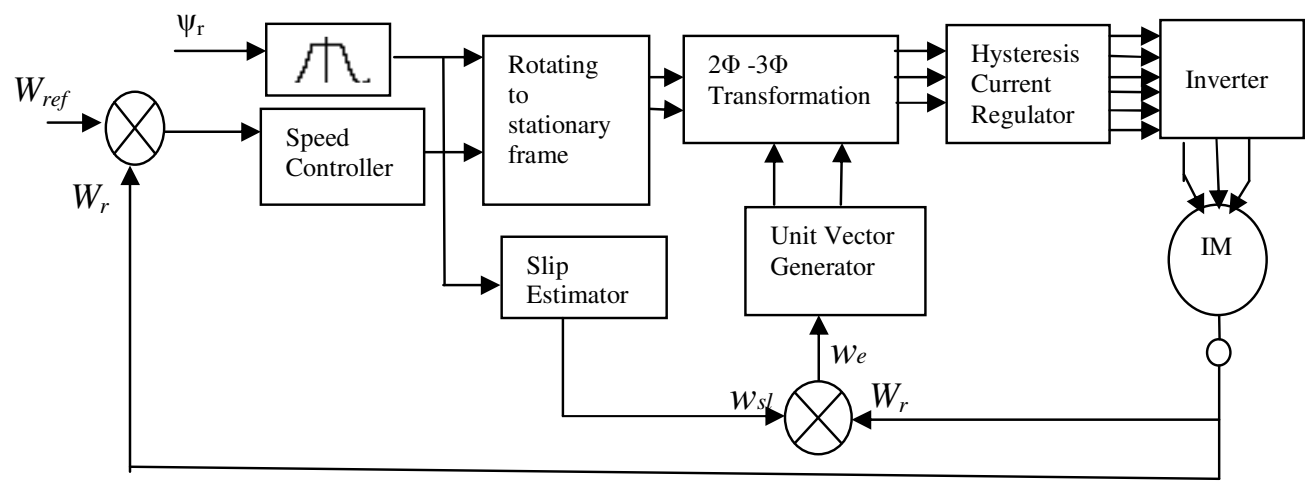

Figure.1 Vector Control Scheme of Induction Motor

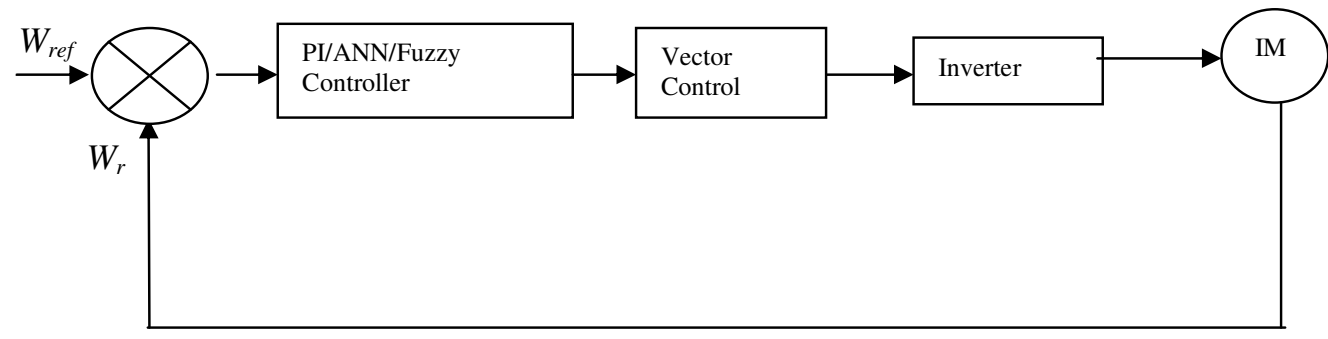

Figure.2 Speed Control of Induction Motor using Intelligent Controller 
When $\mathrm{i}_{\mathrm{qs}}{ }^{*}$ is controlled it affects the actual $\mathrm{i}_{\mathrm{qs}}$ current only, but does not affect the flux $\Psi_{\mathrm{r}}$. Similarly, when $i_{\mathrm{ds}}{ }^{*}$ is controlled, it controls the flux only and does not affect the $\mathrm{i}_{\mathrm{qs}}$ component of current. [1]

With the help of a classical controller PI and various Intelligent controller (FLC \& Neural Network controller), the speed error is converted into a torque controlling current component $i_{\mathrm{q}}$, of the stator current. This current component is used to regulate the torque along with the slip speed. [1]

Figure. 2 shows the block diagram of speed control system using different Controllers.

\section{Artificial Neural Network}

The ANN is an Artificial Intelligent technique which is machine like human brain with properties such as learning capability and generalization. It is a system of interconnecting neurons in a network which work together to form the output function. Neuron is a fundamental processing component of a neural network. [2] The performance of ANN relies on member neurons of network collectively. So that it can still perform its overall function even if some of the neurons are not functioning. Thus, they are very robust to error failure. It required a lot of training to understand the model of the system. To approximate complicated nonlinear functions is the basic property of ANN. [2]

Here, Neural network is used to produce torque producing component of current $\mathrm{i}_{\mathrm{qs}}$. [4], [5]

The input data (error) and output data (torque producing current component) of PI controller are used to train the neural network.

Tansig and Purelin transfer function are used for two input layers. Proper learning rate and proper training parameters are chosen to minimize error. [8]

\section{Fuzzy Logic Speed Controller: Principle and Design}

Basic structure of the fuzzy logic controller to control the speed of the induction motor consists of three important stages: Fuzzification, Decision Making Unit and Defuzzification Unit

The inputs of the Fuzzification Unit are selected as error and rate of change of error. The output of the controller is torque controlling current component. The two input variables error and rate of change of error are calculated at every sampling instant say $n$.

$e(\mathrm{n})=w_{\text {ref }}(\mathrm{n})-w_{\mathrm{e}}(\mathrm{n})$

$\Delta e(\mathrm{n})=w(\mathrm{n})-w(\mathrm{n}-1)$

Where, $w_{\text {ref }}(n)$ is the reference speed at instant $\mathrm{n}$ and $w_{e}(n)$ is measured speed at instant n.[7] In Fuzzification stage the crisp variables e(n) and $\Delta \mathrm{e}(\mathrm{n})$ are converted into fuzzy variables which can be identified by membership function. The fuzzification maps the error and change in error to linguistic labels of fuzzy sets.

The proposed controller uses following linguistic labels: NB (Negative Big), NM (Negative Medium), NS (Negative Small), NVS (Negative Very Small), Z(Zero), PVS (Positive Very Small), PM(Positive Medium), PB(Positive Big). 


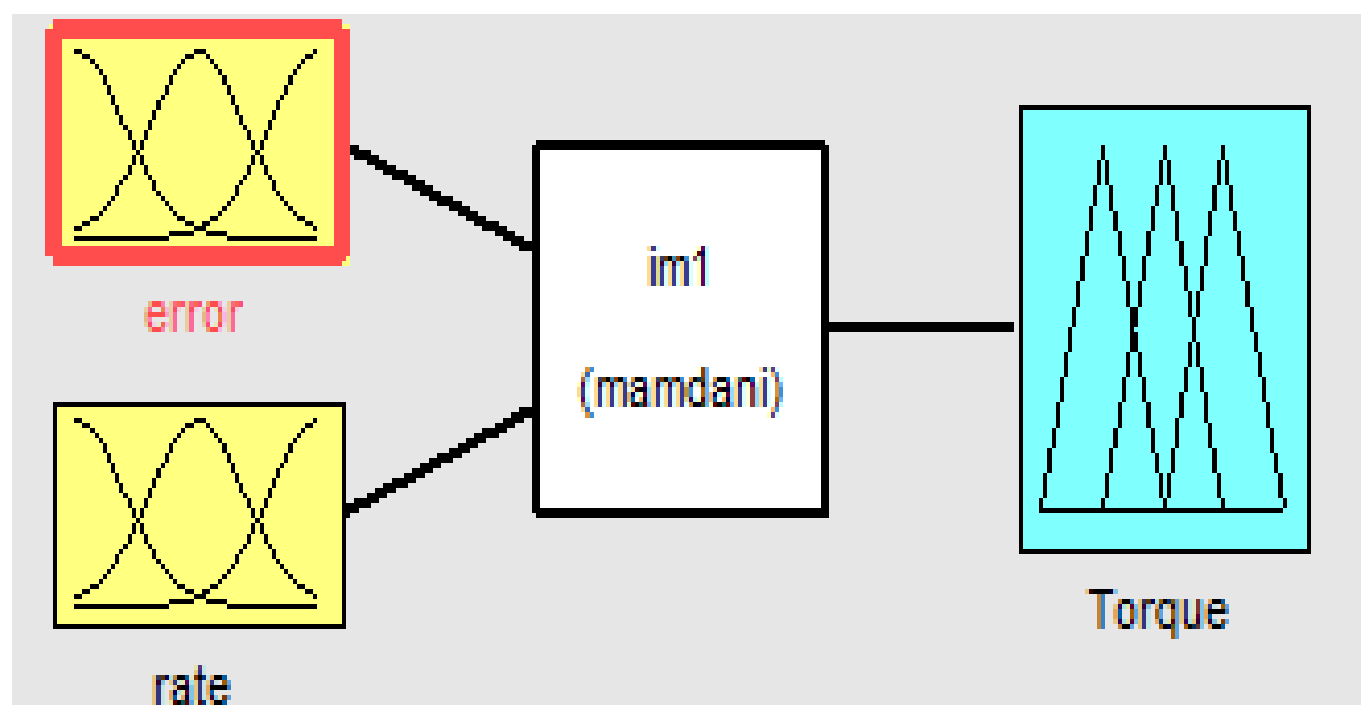

Figure.3 Fuzzy Inference System

Here, the triangular membership functions are used to define both inputs (error and rate of change of error) and output (torque controlling current component).

In the second stage of FLC the input variables are processed by an inference engine that executes 49 rules as shown in Table 1.

Each rule can be interpreted as: If error is Negative Big and rate of change of error is Negative Big then output is Negative Big.

Table 1. Rules Of Fuzzy Logic Controller

\begin{tabular}{|l|l|l|l|l|l|l|l|}
\hline $\mathbf{2} \backslash \mathbf{e}$ & NB & NM & NS & Z & PS & PM & PB \\
\hline NB & NB & NB & NB & NM & NS & NVS & Z \\
\hline NM & NB & NB & NM & NS & NVS & Z & PVS \\
\hline NS & NB & NM & NS & NVS & Z & PVS & PS \\
\hline Z & NM & NS & NVS & Z & PVS & PS & PM \\
\hline PS & NS & NVS & Z & PVS & PS & PM & PB \\
\hline PM & NVS & Z & PVS & PS & PM & PB & PB \\
\hline PB & Z & PVS & PS & PM & PB & PB & PB \\
\hline
\end{tabular}

The output of the decision-making unit is given as input to the de-fuzzification unit and the linguistic format of the signal is converted back into the numeric form of data. In this paper, the center of gravity or centroids method is used to calculate the final output, which finally commands the induction motor via $2 \Phi-3 \Phi$ block. 


\section{Multi Agent Approach:}

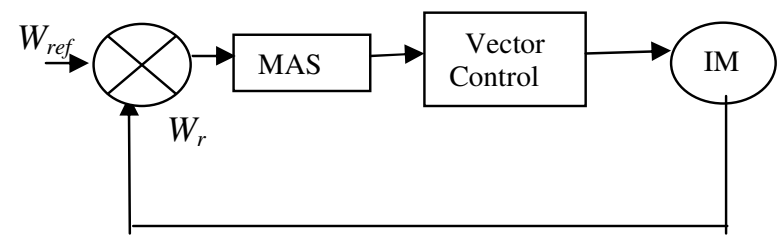

Figure.4 Multi Agent System

Figure.4 shows block diagram of speed control of Induction Motor using Multi Agent System. Frame work of MAS is as shown in figure. 5

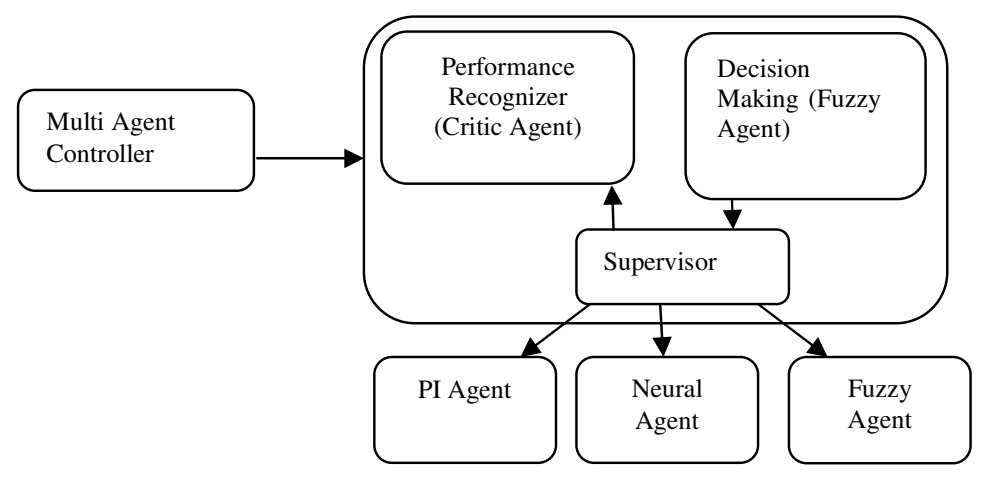

Figure.5 Multi Agent Frame work

\section{Fuzzy Based Supervisor:}

Fig. 6 depicts the working of a supervisor. The user specifies desired system parameters. Critic computes the repsonse parameters from the system. Fuzzy Desion system decides which of the constituents is best under prevailing situation.

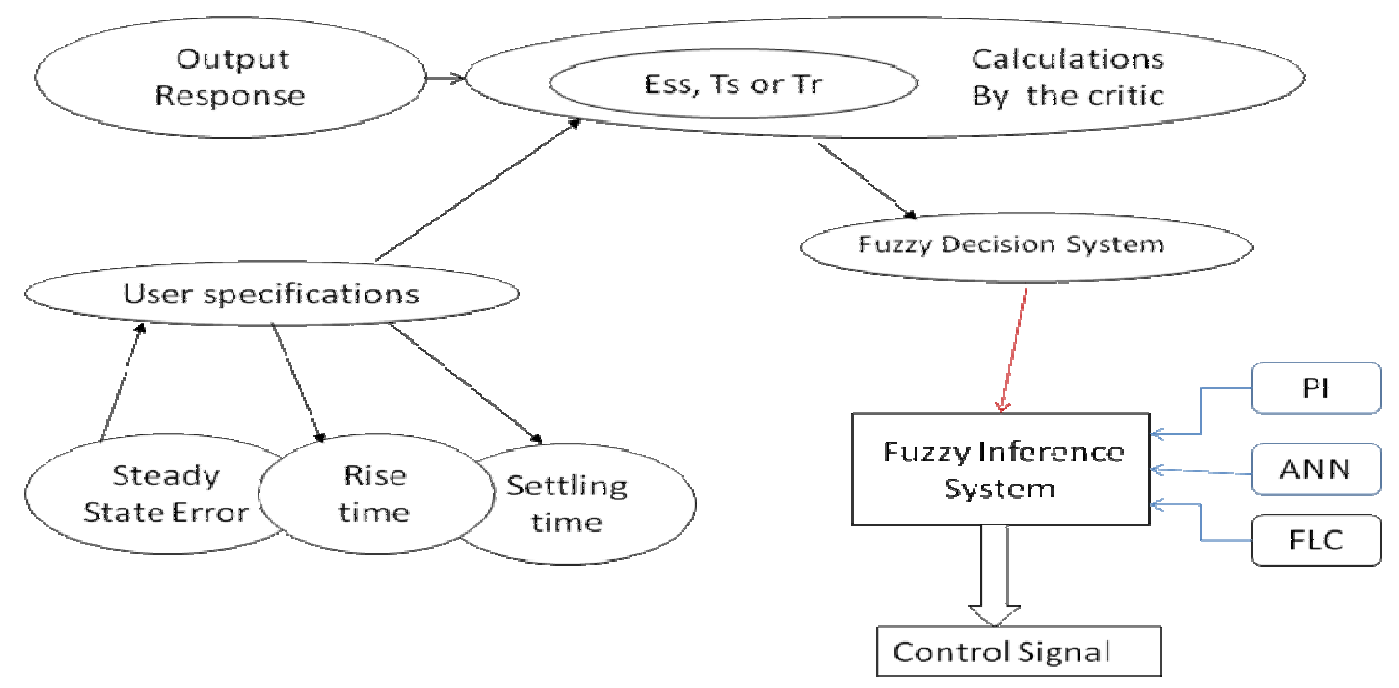

Figure.6 Fuzzy Based Decision Supervisor 


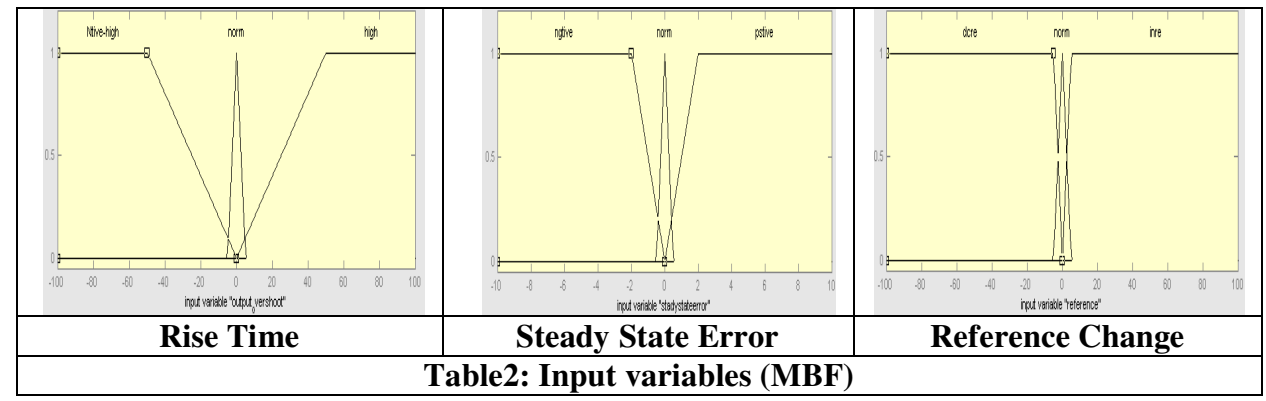

The rule base consists of five rules for selctions of constituent controller as shown in Table 3 .

Table 3. Rules For MAS

\begin{tabular}{|c|c|c|c|c|}
\hline Sr no. & Steady State eroor & Rise Time & Reference change & Controller \\
\hline 1 & High & Low & Low & Neural \\
\hline 2 & Low & High & Low & Fuzzy \\
\hline 3 & Low & Low & High & Neural \\
\hline 4 & High & High & High & Fuzzy \\
\hline 5 & High & High & Low & PID \\
\hline
\end{tabular}

\section{Results and Discussion:}

To implement Multi Agent system the conventional controller (PI), Neural Network Controller \& Fuzzy Logic Controller are developed. All are constructed into MATLAB/SIMULINK environment. Simulation tests were carried out on the PI, Fuzzy and Neural Network Controller. Results are compared in terms of Time response. Fig.7,8 \& 9 shows speed, torque and current responses of different controllers under study including MAS.

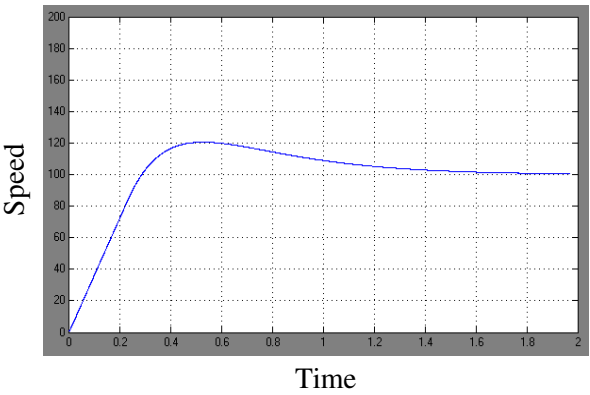

Fig.7 (a) Speed Response using PI Controller

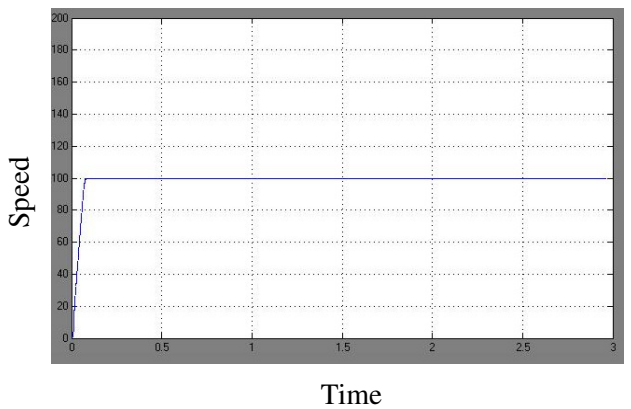

Fig.7 (b) Speed Response using ANN 
International Journal on Soft Computing ( IJSC ), Vol.2, No.3, August 2011

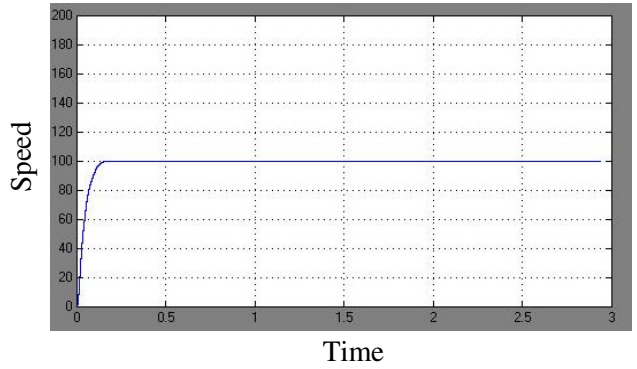

Fig.7 (c) Speed Response using FLC

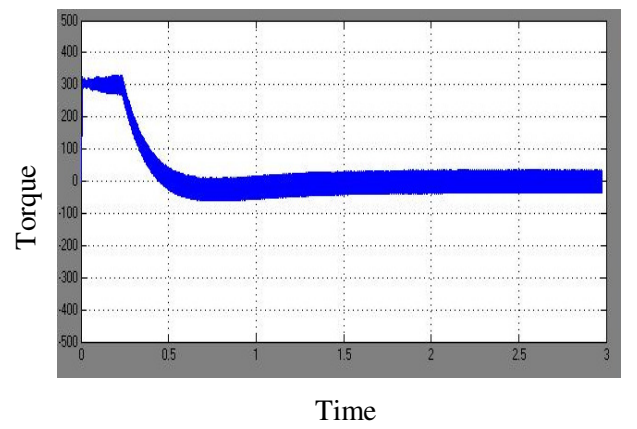

Fig.8 (a) Torque Response using PI Controller

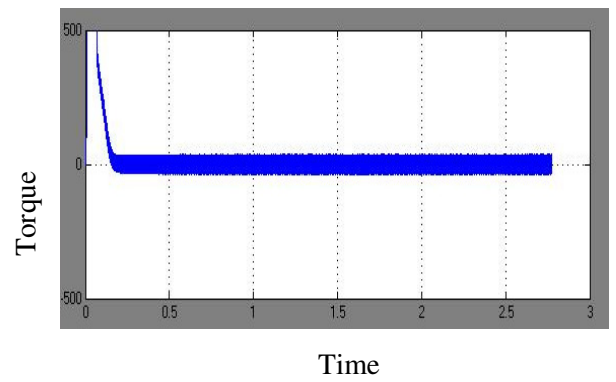

Fig.8 (c )Torque responses using Fuzzy Logic Controller

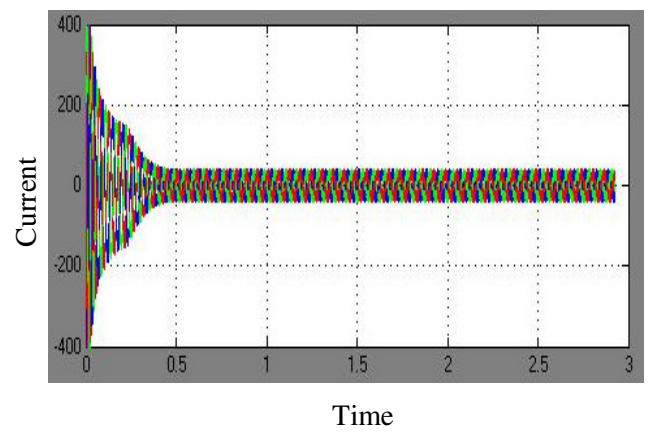

Fig.9 (a) Rotor current response using PI Controller

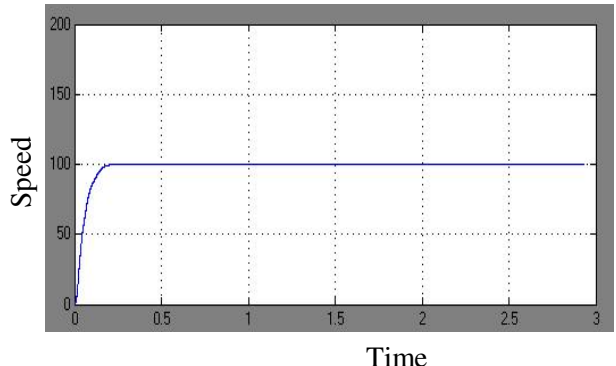

Fig.7 (d) Speed Response using MAS

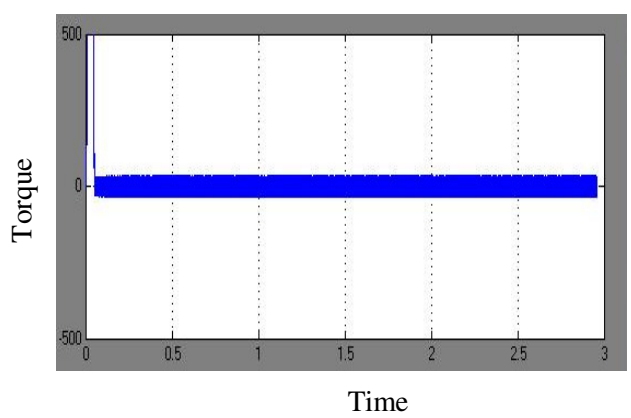

Fig.8(b) Torque Response using ANN

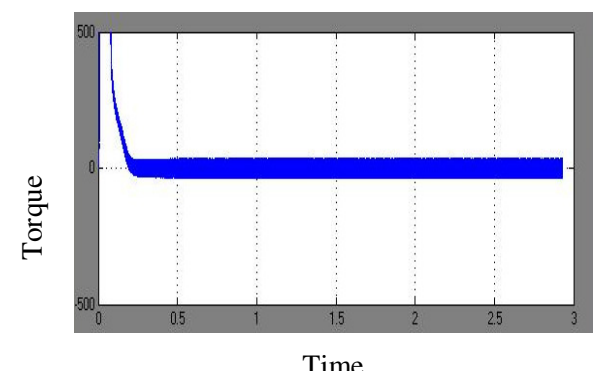

Fig.8 (d) Torque responses using MAS

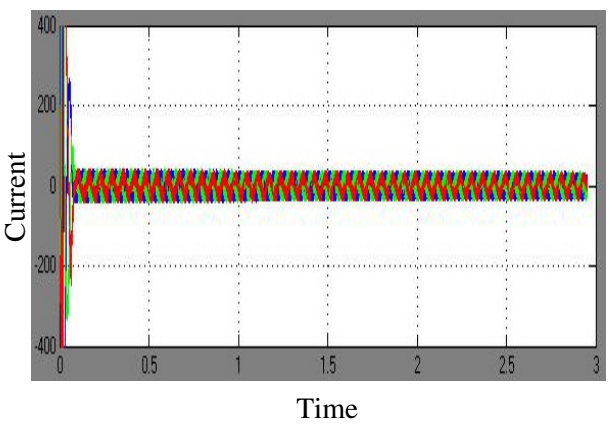

Fig.9 (b) Rotor current response using ANN 


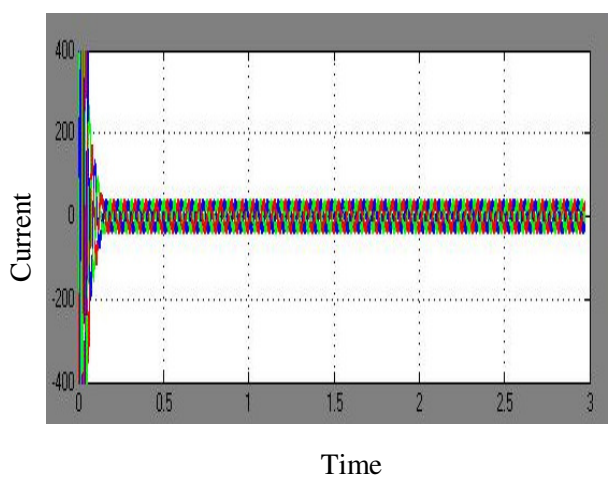

Fig.9 (c ) Current Response using FLC

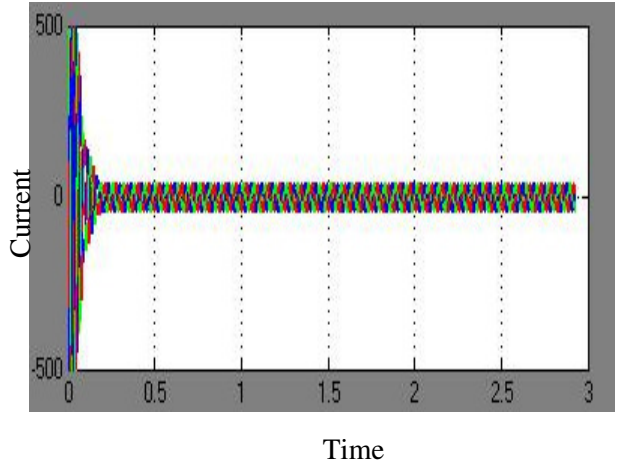

Fig.9 (d) Current Response using MAS

\section{Conclusion:}

SIMULINK Model of Vector control scheme to control speed of Induction motor is developed. Conroller responses of PI, FLC and ANN are compared from simulation From the responses it can be concluded that Fuzzy controller and Neural network controller improves the transient response of Induction machine and dynamic response is made faster.Table 4 depicts the comparison.

Table 4. Comparison Table

\begin{tabular}{|l|l|l|l|}
\hline Controller & $\begin{array}{l}\text { PI } \\
\text { Controll } \\
\text { er }\end{array}$ & ANN Controller & FLC \\
\hline Rise Time & High & $\begin{array}{l}\text { Less compare to PI \& } \\
\text { FLC }\end{array}$ & Less compare to PI \\
\hline SteadyState Error & Large & $\begin{array}{l}\text { Less compare to PI \& } \\
\text { FLC }\end{array}$ & Less compare to PI \\
\hline Overshoot & $20 \%$ & No overshoot & No overshoot \\
\hline
\end{tabular}

Multi Agent framework is prepared. The Multi Agent System is implemented using three controllers (PI, FLC, Neural Network controller). A fuzzy Inference System is designed based on Table 3 for selection of constituent controller for the best response to meet desired response set by the user.

The system is robust to the error failure. Hoever it is found that for the Multi Agent implementation time required to reach steady state value is somewhat higher. This may be reduced by optimization of computational time of critic and FIS. Attemps for GA based advanmced Fuzzy system are under development for fast decisions.

\section{References:}

[1] Power Electronics and motor drives: Advances and Trends By Bimal Bose

[2] MATLAB programming for Engineers, By Stephen J.Chapman 
[3] Albert J.N.Van Breemen, "Agent based Multi-controller system"

[4] Ieroham Baruch, Irving Pavel de la Cruz A., Ruben Garrido," An Indirect Adaptive Vector Control of the Induction Motor Velocity Using Neural Networks"

[5] Miroslaw Wlas, Zbigniew Krzemin’ski, Jarosław Guzin’ski, Haithem Abu-Rub, "Artificial-NeuralNetwork-Based Sensorless Nonlinear Control of Induction Motors", IEEE Transactions On Energy Conversion, Vol. 20, No. 3, September 2005

[6] A. K. Sharma, R. A. Gupta, Laxmi Srivastava," Performance of ANN Based Indirect Vector Control Induction Motor Drive”, Journal of Theoretical and Applied Information Technology, 2007

[7] Norman Mariun, Samsul Bahari Mohd Noor, Jasronita Jasni, Omar S.Bennanes“A Fuzzy Logic based controller for an Indirect Vector controlled Three- Phase Induction motor”, IEEE 2004

[8] www.mathwork.com

\section{Biography:}

Nirali Rathod received her M.E degree from M.S.University of Baroda, India in 2010.

She is working as an Assistant Professor at Sardar Vallabhbhai Patel Institute of Technology, Vasad, Gujarat, India with 10 years of teaching experience. Her areas of interests are in Power systems, Drives, Fuzzy Logic , Neural Network \& Genetic Algorithm.

Prof. Satish Shah is a Head of Electrical Engineering Department at FTE, MS University of Baroda, (Guj) India with $30^{+}$years of teaching and research experience. His primary areas of interest are Embedded Controller and soft computing. He has guided more than hundred projects at UG/PG level.

He is a fellow of technical associations IETE, IE (I), ISA and served as the member, Hon Secretary and Treasurer of local executive committees for a span of six-eight years. He is the Chairman, IETE-Vadodara centre for the year 2010-2012. He is member of IEEE (NY) and a life member of ISTE. He has attended and organized more than 20 seminars, workshops, Symposium under QIP of UGC, AICTE, IETE, IE (I), World Bank Impact project etc. He has conducted faculty training program on "Intelligent Controllers" for the teachers of Engineering colleges and Polytechniques in Gujarat under TECHSAT program of Gujarat Council of Science \& Technology, Gandhinagar. His current areas of interest also include soft computing, Image and Signal processing and smart controller design using DSP. He has presented $20^{+}$research papers in national \& international conferences and published $10^{+}$ research papers in technical journals.
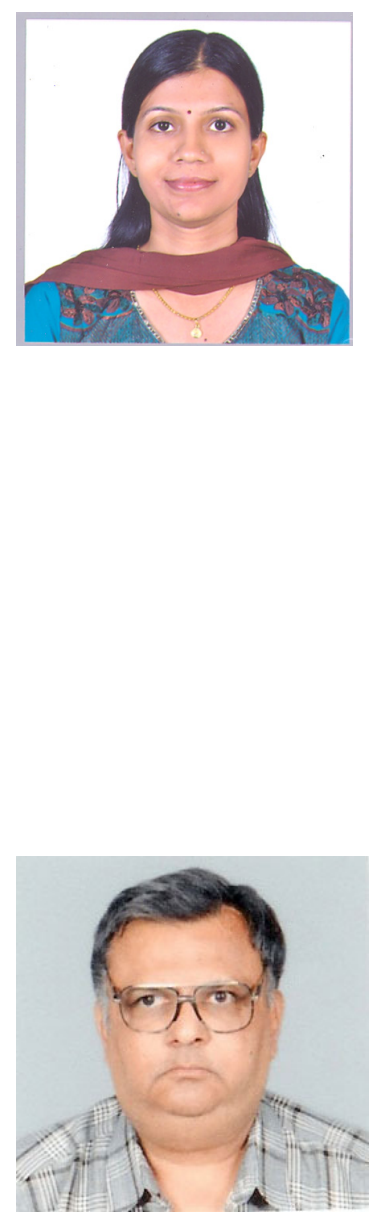